\title{
Clinical recurrence in patients with sequential grafts in Coronary Artery Bypass Graft (CABG) surgery
}

\author{
Recurrencia clínica en pacientes con puentes secuenciales en cirugía de \\ revascularización coronaria
}

\author{
Mario Gómez-Sánchez¹, Roberto Perezgrovas-Olaria²*, Gabriel García-Garnica², Eduardo Bucio-Reta", \\ and Mario E. Rendón-Macías²
}

${ }^{1}$ Department of Research, Cardiac Intensive Care Unit, Instituto Nacional de Cardiología Ignacio Chávez; ${ }^{2}$ Universidad Panamericana School of Medicine, Mexico City, Mexico

\begin{abstract}
Objective: The objective of this study was to compare the recurrence rates of revascularization (redo coronary artery bypass graft [CABG] or percutaneous coronary intervention [PCI]), new ischemic event, or death in patients with simple or sequential grafts in CABG surgery. Methods: The study design is an ambispective cohort of patients that underwent CABG by sequential grafting $(n=111)$ or simple grafting $(n=145)$ between January 1, 2013 and December 31, 2017. Patients had to be 18 years old at the time of surgery, undergoing their first on-pump CABG. The clinical record of every patient was carefully reviewed and patients who had incomplete follow-up in external consultation were contacted by telephone to obtain data about ischemia related reintervention (CABG or PCI), new documented ischemic event, or death caused by coronary artery disease, Kaplan-Meier estimators were calculated. Results: The proportion of recurrence depending on technique was not statistically different: sequential (6.5\% [Cl 95\% 2.6-12.6\%] versus simple 4.8\% [Cl 95\% 2-9.7\%], $p=0.60$, Bayesian analysis $B F_{10}=0.37$; moderate evidence to no difference), each one related to new ischemic event and one death per group. There were no differences in follow-up time (sequential 59m [Cl 95\% 56-62] simple 66m [Cl 95\% 64-68]). No difference was found regarding recurrence incidence rates; sequential 1.99 events $\times 10^{3}$ months-patient, versus simple 1.47 (HR=1.34; Cl 95\% 0.47-3.8, $p=0.58$ ). Pump and cross-clamping times were lower for sequential technique (41.44 min; 24.69 min respectively) versus simple technique (43 min and $26.4 \mathrm{~min}$, respectively) with a $p=0.7$ after adjusting to mean grafts per surgery (2.7 simple; 3.25 sequential, $p<0.001)$. Conclusions: Both techniques had a low incidence of clinical recurrence, without significant differences between procedures.
\end{abstract}

Key words: Sequential grafts. Clinical recurrence. Coronary artery bypass graft surgery.

\section{Resumen}

Objetivo: Comparar las tasas de recurrencia de revascularización coronaria (cirugía o intervención coronaria percutánea), nuevo evento isquémico o muerte en pacientes con puentes secuenciales y con puentes simples. Método: Cohortes

\section{Correspondence:}

${ }^{*}$ Roberto Perezgrovas-Olaria

E-mail: beto.pzgvs@gmail.com
Available online: 02-03-2021

Date of reception: $26-02-2020$

Date of acceptance: 19-03-2020

DOI: 10.24875/ACME.M20000154
Arch Cardiol Mex (Eng). 2020;90(4):431-438 www.archivoscardiologia.com

2604-7063 / C 2020 Instituto Nacional de Cardiología Ignacio Chávez. Published by Permanyer. This is an open access article under the CC BY-NC-ND license (http://creativecommons.org/licenses/by-nc-nd/4.0/). 
ambispectivas de pacientes sometidos a cirugía de revascularización coronaria secuencial $(n=111)$ o simple $(n=145)$ entre el 1 de enero de 2013 y el 31 de diciembre de 2017. Pacientes mayores de 18 años en un primer procedimiento de revascularización, con circulación extracorpórea. Para el seguimiento se realizó revisión del expediente o comunicación telefónica hasta el 9 de febrero de 2019. Se investigaron los siguientes desenlaces: reintervención por isquemia coronaria, nuevo evento isquémico documentado o muerte atribuida a cardiopatía isquémica; también se obtuvieron curvas de sobrevida. Resultados: La proporción de recurrencia según la técnica quirúrgica no fue estadísticamente diferente: secuencial 6.5\% (intervalo de confianza del 95\% [IC 95\%]: 2.6-12.6\%) contra simple 4.8\% (IC 95\%: 2-9.7\%; $p=0.60$; análisis bayesiano $B F_{10}=0.37$; evidencia moderada a no diferencia), todos por nuevo evento isquémico y un fallecimiento por grupo. No hubo diferencias en el tiempo de seguimiento: secuencial 59 meses (IC 95\%: 56-62) y simple 66 meses (IC 95\%: 64-68). No encontramos diferencia en las tasas de incidencia de recurrencia: secuencial 1.99 eventos $/ 10^{3}$ meses-paciente contra simple 1.47 (hazard ratio: 1.34; IC 95\%: 0.47-3.8; $p=0.58$ ). El tiempo promedio de pinzamiento y de circulación extracorpórea por puente fue menor en el grupo de puentes combinados (41.44 minutos de circulación extracorpórea y 24.69 minutos de pinzamiento/puente) que en el de puentes simples (43 minutos en circulación extracorpórea y 26.4 minutos de pinzamiento/ puente) cuando se ajusta al promedio de puentes colocados (simples 2.7 y secuencial 3.25; $p<0.001$ ); sin embargo, no se encontró significancia estadística ( $p=0.7)$. Conclusión: Ambos procedimientos tuvieron una baja incidencia de recurrencia de eventos clínicos, sin diferencias entre las técnicas quirúrgicas.

Palabras clave: Puentes secuenciales. Recurrencia clínica. Revascularización coronaria.

\section{Introduction}

Coronary artery bypass graft (CABG) surgery has represented the ideal treatment for ischemic heart disease in patients with trivascular disease or proximal left coronary artery and anterior descending artery disease, due to the marked decrease in mortality and risk of long-term reoperations in patients who are candidates for surgery in comparison with percutaneous coronary intervention $(\mathrm{PCl})^{1-4}$. On the other hand, CABG offers other additional benefits over $\mathrm{PCl}$, such as angina pectoris correction in more than $90 \%$ of patients undergoing the procedure ${ }^{5}$, as well as a higher rate of mid- and long-term graft patency, which is related to a lower need for revascularization process to be repeated, with procedure-inherent risks, thereby being avoided ${ }^{6}$.

Although CABG advantage over $\mathrm{PCl}$ is clear, there are controversies regarding which blood vessels optimize coronary revascularization. The 2011 American College of Cardiology Foundation/American Heart Association (ACCF/AHA) guidelines for CABG surgery suggest as a Class I recommendation that, in in cases when it is possible, where it is possible, the left internal mammary artery should be used to bypass the left anterior descending artery, with level $B$ evidence ${ }^{7}$. On the other hand, the rest of recommendations in this guidelines regarding the choice of the second conduit in a complete CABG (defined as all epicardial vessels $\geq$ $1.5 \mathrm{~mm}$ with a decrease $\geq 50 \%$ in diameter in at least one angiography view ${ }^{8}$ ) are Class II or Class III in case arterial grafts are used for right coronary artery revascularization if it has $<90 \%$ stenosis?
For patients younger than 70 years, the optimal revascularization strategy is to use the radial artery or the right internal mammary artery as a second conduit, since in this group of patients, CABG with multiple arterial conduits is the main goal. In patients older than 70 years, the radial artery and the right internal mammary artery should be selectively used ${ }^{9}$.

The use of the saphenous vein has been mainly reserved for the right coronary artery grafts when stenosis is $<90 \%$, and the use of arterial conduits is contraindicated. One of the reasons why the use of the saphenous vein is not preferred is because the percentage of these grafts that are found with patency at 1 year of surgery is $75-90 \%$, and $50-60 \%$ at 10 years $^{7,10}$, even when intensive pharmacological management with lipid-lowering drugs and platelet aggregation inhibitors is carried out ${ }^{4}$. On the other hand, more than $90 \%$ of arterial grafts are found to be patent at 10 years of the intervention ${ }^{4,7,10}$.

The most important mechanisms whereby failure of the saphenous vein graft is produced are mainly three, and each one of them predominates at different time periods: acute thrombosis is the main cause of graft failure within the first 30 days after surgery, intimal neo-hyperplasia predominates between the $1^{\text {st }}$ month and 2 years of CABG and, finally, atherosclerosis is the main cause of graft failure after 2 years ${ }^{11}$. Venous graft failure is caused by vein irrigation disruption, which leads to hypoxia and generates accumulation of free radicals that favor graft deterioration ${ }^{4}$. In addition, the mechanical effects caused by pressure change and surgical trauma accelerate graft dysfunction ${ }^{11}$. 
In certain cases, arterial graft harvesting may lead to a slight increase in the risk for developing local or systemic complications. An example of the above is the higher incidence of mediastinal infections associated with the use of both internal mammary arteries in some patients with risk factors described in the literature (diabetes mellitus, obesity, and chronic obstructive pulmonary disease), since the use of these conduits as pediculated grafts decreases sternal wall irrigation $n^{4,6,8,12}$. Another example is observed when the radial artery is used for grafts, because paresthesia may occur in the arm that the artery is obtained from in approximately one third of patients, although these symptoms are not that important since they are generally transient and self-limited when collaterality is appropriate ${ }^{13}$, which is why the Allen test should be done, accompanied by a second test, such as Doppler ultrasound, pulse oximetry, or digital pressure measurement with radial artery obstruction before using it as graft in a revascularization procedure ${ }^{6}$.

The use of the left internal mammary artery to irrigate the anterior descending artery is mainly based in two aspects: (1) its privileged anatomical distribution, which allows reaching the anterior descending artery in most patients without having to place bypass grafts directly from the aorta ${ }^{5}$, whereby the risk of embolism due to atherosclerotic plaques dislodging from the ascending aorta is decreased ${ }^{8,14}$ and (2) low development of atherosclerosis in the long-term, since less than $4 \%$ of internal mammary arteries have been documented to develop atherosclerosis, with only $1 \%$ generating hemodynamically significant atherosclerosis ${ }^{7}$.

The intrinsic mechanisms by which the internal mammary artery does not develop atherosclerosis are well known and have been widely studied, with structural factors, such as a lower number of endothelial fenestrations and intercellular junctions, lower patency, coupled with a series of biochemical factors, such as increased synthesis of antithrombotic molecules (heparan sulfate and tissue plasminogen activator) and an increased production of nitric oxide, having been found to be fundamental aspects in the resistance of this vessel to atherosclerosis ${ }^{4}$. Another important point is that, by having a diameter similar to that of the coronary arteries, flow at anastomotic site does not become turbulent, thereby preventing platelet aggregation and thrombi formation ${ }^{4}$.

Finally, the placement of arterial grafts (particularly of the internal mammary artery and radial artery) has been described to have a protective effect on native coronary arteries since a decrease in the progression of coronary atherosclerosis has been observed compared to saphenous vein grafts ${ }^{10}$.

All the above indicates that it is better to perform a more complete CABG using as many arterial grafts as possible, to maintain long-term patency and stop the development of atheroma plaques in the coronary arteries ${ }^{10}$. Employing a sequential grafting technique, which consists of two or more distal anastomoses made with the same conduit, might facilitate the development of more complete revascularizations in less surgical time when compared to single grafts, where only one distal anastomosis for each conduit is performed ${ }^{15,16}$, which would decrease aortic cross-clamping and cardiopulmonary bypass times, which are important morbidity and mortality predictors in cardiac surgery ${ }^{17,18}$.

In a meta-analysis carried out by Li et al. ${ }^{19}$, absolute risk of sequential venous grafts occlusion was found to be $13.56 \%$, in comparison with an occlusion risk of $19.18 \%$ in the group of single grafts.

One of the main reasons sequential grafting has been criticized is because, theoretically, a proximal occlusion of the main graft would entail higher risk for the patient, due to the fact that, the amount of affected myocardium would be larger than if only one graft's flow was obstructed, as it would occur with a single graft ${ }^{19}$. This study aims to be useful for therapeutic decision-making regarding what type of graft favors complete revascularization of patients' coronary irrigation system, taking as reference the recurrence of clinical events over time. The hypothesis supported in this work is that recurrence of clinical events with sequential grafting in CABG surgery is lower than with single grafts. The general purpose of this study is to determine if adults with ischemic heart disease undergoing CABG surgery using sequential grafts have a lower recurrence of clinical events than those undergoing revascularization using single grafts.

\section{Methods}

The medical records of 378 patients who underwent CABG surgery between January 1, 2013, and December 31, 2017 were reviewed. Patients who died in the immediate or late postoperative period from causes other than failure of the inserted grafts were initially excluded from the study. Patients included in the study were divided in two large groups to determine clinical events recurrence: (1) those with complete follow-up in the outpatient setting and (2) those who interrupted outpatient follow-up. The first group was followed-up through outpatient clinical notes, while the second 
group was administered a questionnaire specifically designed to assess the recurrence of clinical events by telephone, with all those patients in whom the questionnaire could not be applied being eliminated from the study. Finally, the events were reported according to the type of surgically-placed graft, with two final groups being established: only single grafts $(n=145)$ and sequential or combined grafts (at least one single and one sequential graft; $n=111$ ) (Tables 1 and 2).

Absolute confidentiality regarding patient's data was maintained at all times and information of none of them was ever disclosed with anyone external to the protocol. (Fig. 1).

\section{Results}

Demographic data analysis showed that both groups were highly homogeneous when the percentages of patients who had an associated risk factor for developing coronary artery disease were compared (Table 1). The main difference that was found is related to surgical times: in the group of single grafts, mean aortic cross-clamping time was $71.37 \pm 23 \mathrm{~min}$, while, in the combined/sequential group, it was $80.3 \pm 24 \mathrm{~min}$ $(p=0.0035)$. Similarly, average cardiopulmonary bypass time in the single grafts group was found to be $116.24 \pm 30 \mathrm{~min}$, in contrast with the combined group time, which was estimated to be $134.78 \pm 34 \mathrm{~min}$ $(p<0.001)$. On the other hand, average number of grafts placed in the group of single grafts was found to be 2.7, in contrast with 3.25 in the combined group $(p<0.001)$. Finally, when all the above data was individually analyzed, we found that average time for each graft tends to be lower in the group of combined grafts (41.44 min on cardiopulmonary bypass and $24.69 \mathrm{~min}$ of cross-clamping for each graft), in comparison with the group of simple grafts (43 min on cardiopulmonary bypass and $26.4 \mathrm{~min}$ of cross-clamping for each graft); however, no statistical significance was found between both groups ( $p=0.7$ ) (Figs. 2 and 3 ). The proportion of recurrence (clinical events, infarction or mortality) according to the surgical technique was not statistically different: sequential 6.5\% (95\% confidence interval [Cl]: 2.6-12.6) and single 4.8\% (95\% Cl: 2-9.7\%; $p=0.60$; Bayesian analysis $\mathrm{BF}_{10}=0.37$; moderate evidence to no difference); all due to a new ischemic event and one death per group (Fig. 4). There were no differences in follow-up time: sequential $59 \mathrm{~min}$ (95\% Cl: 56-62) and single 66 min (95\% Cl: 64-68). We found no difference in recurrence incidence rates: sequential 1.99 events $/ 10^{3}$

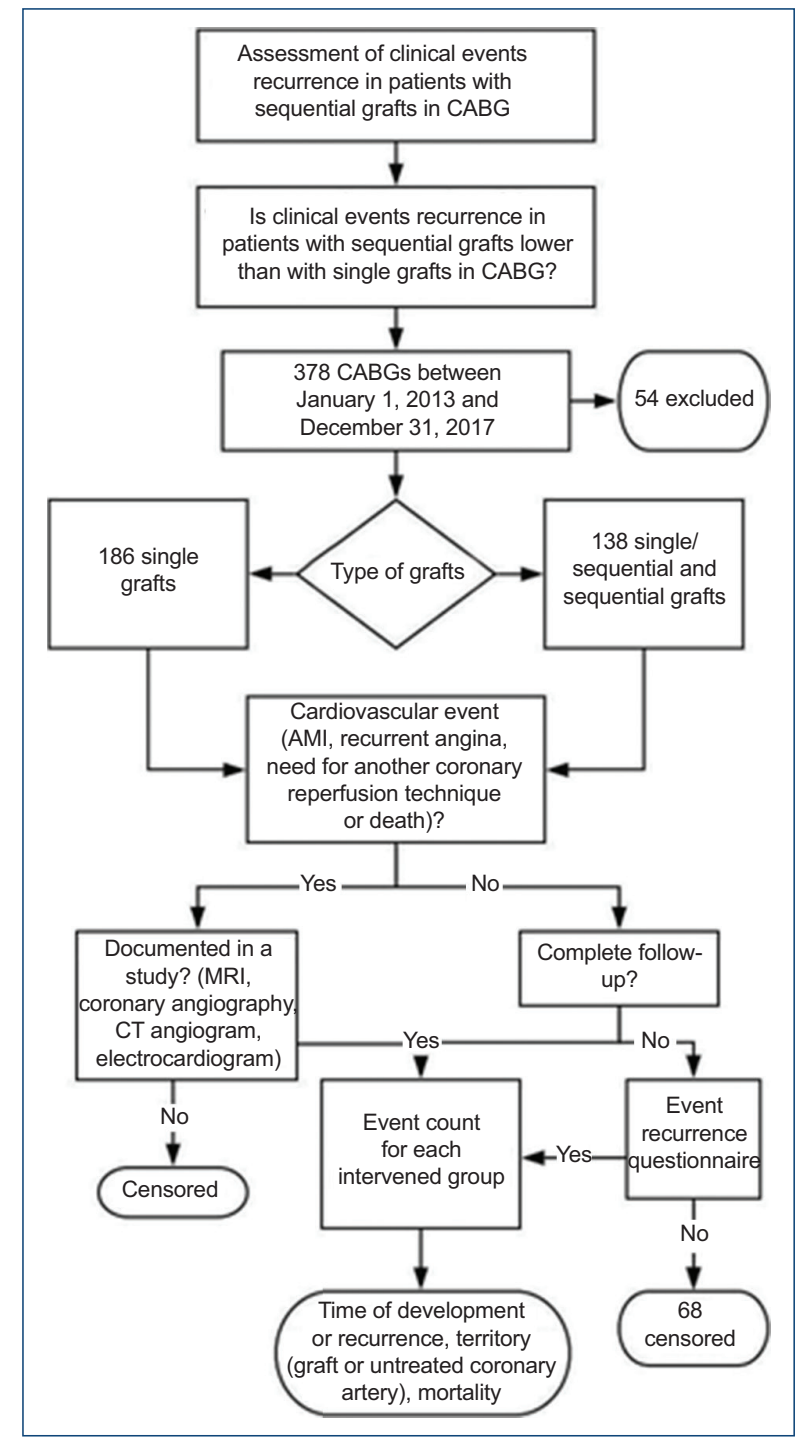

Figure 1. Flowchart illustrating the employed methodology. AMI: acute myocardial infarction; CABG: coronary artery bypass grafting; CT angiogram: computed tomography angiogram.

patient-months and single 1.47 events $/ 10^{3}$ patient-months (hazard ratio: $1.34 ; 95 \% \mathrm{Cl}: 0.47-3.8 ; \mathrm{p}=0.58$ ).

\section{Discussion}

In a study carried out by Mehta et al. ${ }^{15}$, the use of sequential grafts employing the saphenous vein as conduit in CABG was associated with higher graft failure at 1 year (> 75\% arterial lumen obstruction) and with a higher incidence of clinical events (acute myocardial infarction, need for another coronary revascularization or death) at 5 years of the procedure, in comparison with the use of single grafts with the same conduit, 
Table 1. Patient demographic characteristics according to the type of graft

\begin{tabular}{|c|c|c|}
\hline \multirow[t]{2}{*}{ Variable } & Single and sequential grafts ( $n=111$ ) & Single grafts $(n=145)$ \\
\hline & (n \%) & $(n \%)$ \\
\hline Mean age (years) & 60.9 & 62.0 \\
\hline Obesity & $23(20.7)$ & $38(26.2)$ \\
\hline Hypertension & $65(58.6)$ & $103(71)$ \\
\hline Smoking & $62(55.9)$ & $75(51.7)$ \\
\hline Diabetes mellitus & $55(49.5)$ & $78(53.8)$ \\
\hline Dyslipidemia & $53(47.8)$ & $62(42.8)$ \\
\hline $\begin{array}{l}\text { Chronic kidney disease } \\
\text { Stage } 3 \\
\text { Stage } 4 \\
\text { Stage } 5\end{array}$ & $\begin{array}{c}6(5.4) \\
0 \\
0\end{array}$ & $\begin{array}{c}2(1.4) \\
0 \\
1(0.7)\end{array}$ \\
\hline $\begin{array}{l}\text { Functional class (NYHA): } \\
\text { I } \\
\text { II } \\
\text { III } \\
\text { IV }\end{array}$ & $\begin{array}{c}52(46.9) \\
49(44.1) \\
9(8.1) \\
1(0.9)\end{array}$ & $\begin{array}{c}60(41.4) \\
75(51.7) \\
8(5.5) \\
2(1.4)\end{array}$ \\
\hline $\begin{array}{l}\text { Congestive heart failure class: } \\
\text { B } \\
\text { C } \\
\text { Peripheral artery disease } \\
\text { Previous infarction } \\
\text { Previous angioplasty } \\
\text { Trivascular disease } \\
\text { Mean LVEF (\%) } \\
\text { EuroSCORE mean }\end{array}$ & $\begin{array}{c}1(0.9) \\
1(0.9) \\
0 \\
63(56.8) \\
18(16.2) \\
86(77.4) \\
52.92 \\
2.44\end{array}$ & $\begin{array}{c}3(2.1) \\
0 \\
1(0.7) \\
74(51) \\
27(18.6) \\
123(84.8) \\
52.9 \\
2.08\end{array}$ \\
\hline $\begin{array}{l}\text { EuroSCORE: } \\
\text { Low (0-2\%) } \\
\text { Intermediate (2-5\%) } \\
\text { High }(>5 \%)\end{array}$ & $\begin{array}{l}74(66.7) \\
23(20.8) \\
14(12.7)\end{array}$ & $\begin{array}{c}96(66.2) \\
40(27.6) \\
9(6.2)\end{array}$ \\
\hline $\begin{array}{l}\text { Type of surgery } \\
\text { Elective } \\
\text { Emergency }\end{array}$ & $\begin{array}{c}103(92.7) \\
8(7.2)\end{array}$ & $\begin{array}{c}140(96.6) \\
5(3.4)\end{array}$ \\
\hline $\begin{array}{l}\text { Type of ischemic heart disease: } \\
\text { Stable angina } \\
\text { Unstable angina } \\
\text { Non-STEACS } \\
\text { STEACS } \\
\text { Arrhythmia } \\
\text { Dilated cardiomyopathy } \\
\text { Bleeding mean (mL) }\end{array}$ & $\begin{array}{c}43(38.8) \\
18(16.3) \\
34(30.6) \\
15(13.5) \\
1(0.9) \\
0 \\
609.48\end{array}$ & $\begin{array}{c}45(31) \\
34(23.5) \\
44(30.3) \\
21(14.5) \\
0 \\
1(0.69) \\
630.77\end{array}$ \\
\hline
\end{tabular}

LVEF: left ventricular ejection fraction; Non-STEACS: Non-ST-segment elevation acute coronary syndrome; NYHA: New York Heart Association; STEACS: ST-segment elevation acute coronary syndrome.

which was not reflected in our study, since most obstructed conduits in our experience were arterial and not venous, single and not sequential (Fig. 5). In contrast to the above, in the study published by Kim et al..$^{20}$, sequential grafts, patency was found to be superior to that of single grafts in the mid-term, which was not clearly seen in our study either since the results extrapolated to the individualized type of graft were very similar and not significant. On the other hand, Ouzounian et al. ${ }^{16}$ reported that the use of sequential grafts is not a predictive factor for a larger number of adverse events or a poorer long-term prognosis when comparing patients who received sequential or single grafts, with this study being the one that most agrees with our 
Arch Cardiol Mex (Eng). 2020;90(4)

Table 2. Questionnaire for the assessment of coronary artery disease-associated clinical events recurrence Questionnaire for assessment of clinical events recurrence in patients who underwent revascularization

Name: $\quad$ Medical record number:

Angina pectoris

1. After surgery, have you experienced oppressive chest pain similar to that before the operation? (With cold, the postprandial state, or physical effort as possible triggering factors)

Time: I do not have angina (CCS 0)

Angina only with strenuous or prolonged activity (CCS 1)

Angina with accelerated walking without slope. Walking uphill or climbing more than one flight of stairs (CCS 2)

Angina when walking at normal pace 1-2 blocks or climbing one flight of stairs (CCS 3)

Angina even with slight physical exertion or at rest (CCS 4)

\section{Dyspnea}

2. Feeling of shortness of breath when walking:

Time I do not have shortness of breath with usual activity (NYHA I)

I have shortness of breath with usual activity (NYHA II)

I have shortness of breath when walking short distances, one block or 20-100 meters (NYHA III)

I have shortness of breath at rest (NYHA IV)

\section{Medication use}

3. Are you taking your medication?
3.1. Platelet aggregation inhibitors (aspirin, aspirin + clopidogrel or clopidogrel)
3.2. Statins
3.3. Beta-blockers

\section{CHF development}

4. In your sleep, have you suddenly felt shortness of breath, which makes you wake up?

5. Do you need to sleep with more than one pillow not to feel you're choking?

\section{Mood}

6. How does the health of your heart make you emotionally feel since you were operated?

Fine, my mood has improved since the procedure

There have been no changes in my mood

Bad, my mood has worsened since the procedure

CHF: congestive heart failure.

results, which is why it can be speculated that the quality of the surgical technique is the main determining factor for conduit patency to be maintained after CABG (Table 1).

The limitations of this study include the fact that we did not consider the time in the cardiac intensive care unit for each group, and that each graft that was placed could have been independently counted, reporting raw events only, without categorizing the patients in a combined group, which might be a confounding variable. Not having assessed patency is also a weakness of this study since, by exclusively considering clinical parameters, the actual degree of obstruction of the coronary arteries cannot be known. 


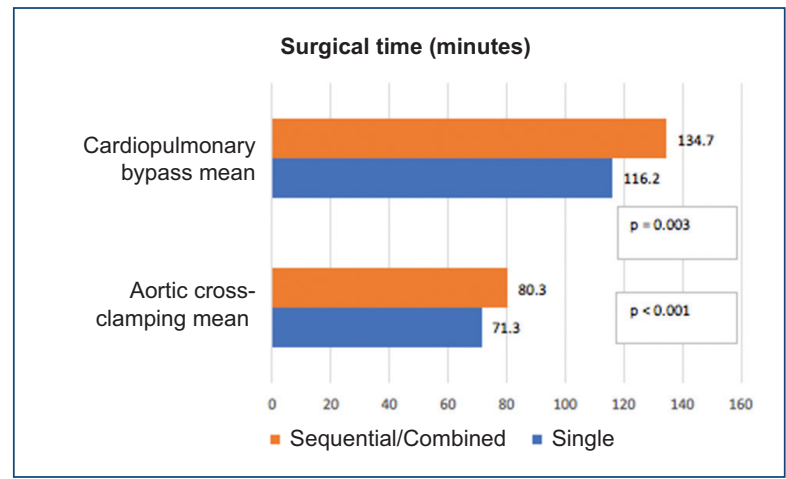

Figure 2. Cardiopulmonary bypass and clamping times comparison with no adjustment for grafts.

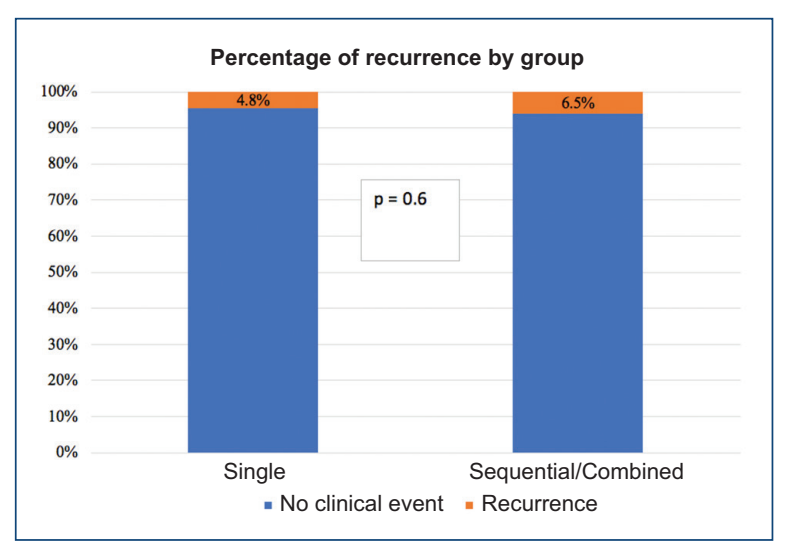

Figure 4. Comparison of recurrences between both groups.

\section{Conclusions}

The use of single or sequential grafts in CABG shows no significant differences in terms of recurrence of clinical events in patients. We consider that therapeutic decision-making regarding the revascularization technique should be individualized for each patient. Similarly, sequential grafts were shown to allow a more complete revascularization, and this could be particularly useful in those patients with a limited number of grafts with suitable characteristics for the placement of a graft that maintains patency over time.

\section{Funding}

This research has not received any specific grant from agencies of the public, commercial, or non-profit sectors.

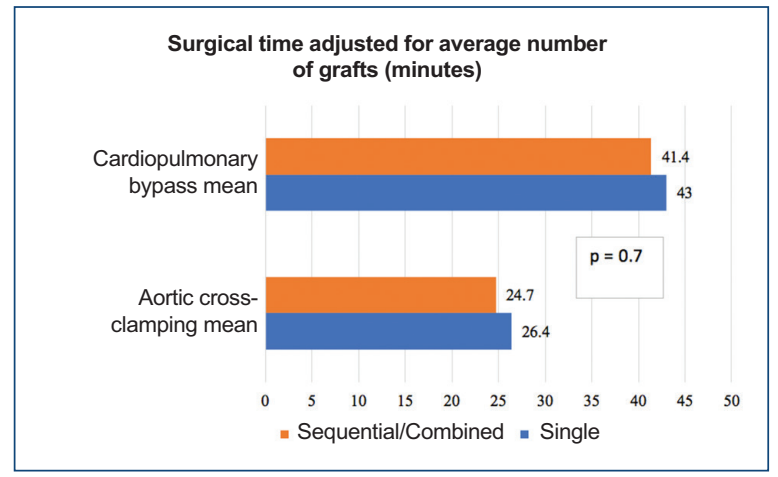

Figure 3. Cardiopulmonary bypass and clamping times comparison with adjustment for average grafts per group.

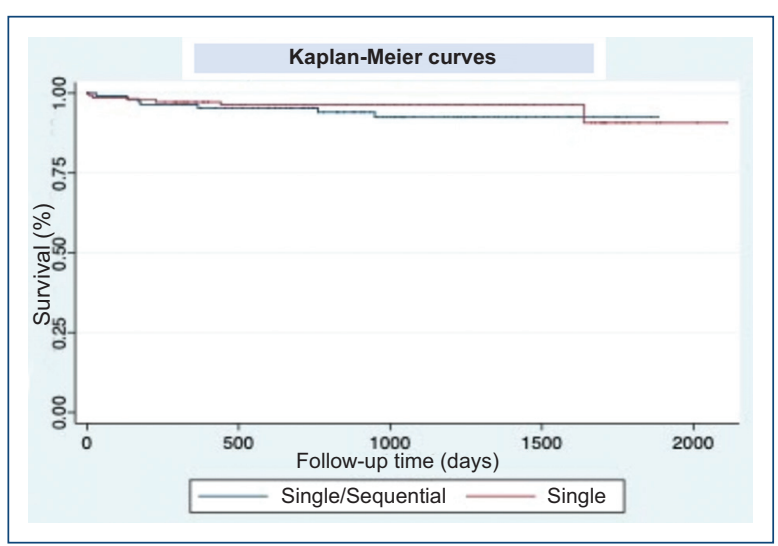

Figure 5. Survival estimators in both groups.

\section{Conflicts of interests}

The authors declare that there are no conflicts of interest.

\section{Ethical disclosures}

Protection of human and animal subjects. The authors declare that no experiments were performed on humans or animals for this research.

Confidentiality of data. The authors declare that they have followed the protocols of their work center on the publication of patient data.

Right to privacy and informed consent. The authors declare that no patient data appear in this article.

\section{References}

1. Habib R, Dimitrova K, Badour S, Yammine M, El-Hage-Sleiman A, Hoffman D. CABG versus PCI. JACC. 2015;66:1417-27. 
2. Weintraub W, Grau-Sepulveda M, Weiss J, O'Brien S, Peterson E, Kolm $P$, et al. Comparative effectiveness of revascularization strategies. N Engl J Med. 2012;366:1467-76.

3. Sipahi I, Akay H, Dagdelen S, Blitz A, Alhan C. Coronary artery bypass grafting vs percutaneous coronary intervention in multivessel disease - reply. JAMA Int Med. 2014;174:1007.

4. Otsuka F, Yahagi K, Sakakura K, Virmani R. Why is the mammary artery so special and what protects it from atherosclerosis? Ann Cardiothorac Surg. 2013;2:519-26.

5. Pevni D, Mohr R, Lev-Ran O, Paz Y, Kramer A, Frolkis I, et al. Technica aspects of composite arterial grafting with double skeletonized internal thoracic arteries. Chest. 2003;123:1348-54.

6. Aldea G, Bakaeen F, Pal J, Fremes S, Head S, Sabik J, et al. The Society of Thoracic Surgeons clinical practice guidelines on arterial conduits for coronary artery bypass grafting. Ann Thorac Surg. 2016:101:801-9.

7. Hillis L, Smith P, Anderson J, Bittl J, Bridges C, Byrne J, et al. 2011 ACCF/ AHA guideline for coronary artery bypass graft surgery: a report of the American College of Cardiology Foundation/American Heart Association Task Force on Practice Guidelines. Circulation. 2011;124:e652-e735.

8. Kolh P, Windecker S, Alfonso F, Collet J, Cremer J, Falk V, et al. 2014 ESC/EACTS guidelines on myocardial revascularization. Eur J Cardiothorac Surg. 2014;46:517-92.

9. Tranbaugh R, Schwann T, Swistel D, Dimitrova K, Al-Shaar L, Hoffman D, et al. Coronary artery bypass graft surgery using the radial artery, right internal thoracic artery, or saphenous vein as the second conduit. Ann Thorac Surg. 2017;104:553-9.

10. Dimitrova K, Hoffman D, Geller C, Dincheva G, Ko W, Tranbaugh R. Arterial grafts protect the native coronary vessels from atherosclerotic disease progression. Ann Thorac Surg. 2012;94:475-81.

11. Harskamp R, Lopes R, Baisden C, de Winter R, Alexander J. Saphenous vein graft failure after coronary artery bypass surgery. Ann Surg. 2013;257:824-33.
12. Dorman M, Kurlansky P, Traad E, Galbut D, Zucker M, Ebra G. Bilateral internal mammary artery grafting enhances survival in diabetic patients: a 30-year follow-up of propensity score-matched cohorts. Circulation. 2012:126:2935-42.

13. Holman W, Davies J, Lin J, Wang Y, Goldman S, Bakaeen F, et al. Consequences of radial artery harvest. JAMA Surg. 2013;148:1020-3.

14. Moss E, Puskas J, Thourani V, Kilgo P, Chen E, Leshnower B, et al. Avoiding aortic clamping during coronary artery bypass grafting reduces postoperative stroke. J Thorac Cardiovascr Surg. 2015;149:175-80.

15. Mehta R, Ferguson T, Lopes R, Hafley G, Mack M, Kouchoukos N, et al. Saphenous vein grafts with multiple versus single distal targets in patients undergoing coronary artery bypass surgery: one-year graft failure and five-year outcomes from the Project of Ex-Vivo Vein Graft Engineering via Transfection (PREVENT) IV Trial. Circulation. 2011:124:280-8.

16. Ouzounian M, Hassan A, Yip AM, Buth KJ, Baskett RJ, Ali IS, et al. The impact of sequential grafting on clinical outcomes following coronary artery bypass grafting. Eur J Cardiothorac Surg. 2010:38:579-84.

17. Al-Sarraf N, Thalib L, Hughes A, Houlihan M, Tolan M, Young V, et al. Cross-clamp time is an independent predictor of mortality and morbidity in low- and high-risk cardiac patients. Int J Surg. 2011:9:104-9.

18. Salis S, Mazzanti V, Merli G, Salvi L, Tedesco C, Veglia F, et al. Cardiopulmonary bypass duration is an independent predictor of morbidity and mortality after cardiac surgery. J Cardiothorac Vasc Anesth. 2008;22:814-22.

19. Li J, Liu Y, Zheng J, Bai T, Liu Y, Wang X, et al. The patency of sequential and individual vein coronary bypass grafts: a systematic review. Ann Thorac Surg. 2011;92:1292-8.

20. Kim H, Lee T, Kim J, Cho W, Jung S, Chung C, et al. The impact of sequential versus single anastomoses on flow characteristics and midterm patency of saphenous vein grafts in coronary bypass grafting. $J$ Thorac Cardiovasc Surg. 2011;141:750-4. 